\title{
Processing of regular and irregular past tense morphology in highly proficient second language learners of English: a self-paced reading study
}

Article

Accepted Version

Pliatsikas, C. and Marinis, T. (2013) Processing of regular and irregular past tense morphology in highly proficient second language learners of English: a self-paced reading study. Applied Psycholinguistics, 34 (5). pp. 943-970. ISSN 14691817 doi: https://doi.org/10.1017/S0142716412000082 Available at https://centaur.reading.ac.uk/26605/

It is advisable to refer to the publisher's version if you intend to cite from the work. See Guidance on citing.

To link to this article DOI: http://dx.doi.org/10.1017/S0142716412000082

Publisher: Cambridge University Press

All outputs in CentAUR are protected by Intellectual Property Rights law, including copyright law. Copyright and IPR is retained by the creators or other copyright holders. Terms and conditions for use of this material are defined in the End User Agreement. 


\section{CentAUR}

Central Archive at the University of Reading

Reading's research outputs online 


\section{Processing of regular and irregular past tense morphology in highly proficient L2}

learners of English: a self-paced reading study

Short title: Processing of regular and irregular verbs in L2

Christos Pliatsikas \& Theodoros Marinis

University of Reading

Department of Clinical Language Sciences 


\begin{abstract}
Dual-system models suggest that English past tense morphology involves two processing routes: rule application for regular verbs and memory retrieval for irregular verbs (Pinker, 1999). In second language (L2) processing research, Ullman (2001a) suggested that both verb types are retrieved from memory, but more recently Clahsen and Felser (2006) and Ullman (2004) argued that past tense rule application can be automatised with experience by L2 learners. To address this controversy, we tested highly proficient Greek-English learners with naturalistic or classroom L2 exposure compared to native English speakers in a self-paced reading task involving past tense forms embedded in plausible sentences. Our results suggest that, irrespective to the type of exposure, proficient L2 learners of extended L2 exposure apply rule-based processing.
\end{abstract}


During the last decade, a considerable number of researchers have turned their attention to processing of grammar in a second language (L2) using on-line behavioural and neuro-imaging methods. Some models suggest that grammatical rules of L2 are never automatised by L2 learners, but are learned declaratively and are consciously applied when necessary (Ullman, 2001a). According to this view, L2 learners cannot process the grammar of their L2 like native speakers. According to a second model, only some types of rules can be automatised, and their automatisation is subject to L2 learners' level of proficiency and exposure to the L2 (Clahsen \& Felser, 2006). Finally, according to a third view, L2 learners can achieve native-like processing irrespective of the structure tested (Gillon-Dowens, Vergara, Barber, \& Carreiras, 2010; Hopp, 2010). L2 processing is influenced by a number of factors that do not apply in native language (L1) processing, such as age of onset of L2 acquisition, proficiency level, exposure in a L2-speaking environment, and everyday use of the L2 (see Grosjean, 1998, for a review). To date, several studies have investigated the impact of proficiency on L2 processing (Hahne, 2001; Kirkici, 2005; Rossi, Gugler, Friederici, \& Hahne, 2006), but very few studies have investigated the role of exposure type on L2 processing (Dussias, 2003; Dussias \& Sagarra, 2007; Frenck-Mestre, 2002; Morgan Short, Sanz, Steinhauer, \& Ullman, 2010; Pliatsikas \& Marinis, under review). The present study addresses the controversy surrounding L2 processing by investigating real-time processing of inflection in L2 learners of English. To address whether or not type of exposure affects L2 processing, we compare a group of L2 learners with naturalistic exposure to a group of L2 learners with only classroom exposure to English and a group of native speakers of English. 


\section{Processing of inflection in $\mathrm{L1}$}

There are two types of past tense forms in English: regular past tense forms, where a suffix (-ed) is attached to the verb stem (e.g.: play-played), and irregular past tense forms, where the past tense form is created in an unpredictable fashion (e.g.: eat-ate). Previous research has revealed important differences between the two verb types; for example, irregular past tense forms are subject to form frequency effects (Pinker, 1999). This has resulted into a 20 -year-old debate on how past tense inflection is processed (Pinker \& Prince, 1988; Pinker \& Ullman, 2002). One viewpoint argues for a dual-system model of inflectional processing (Pinker, 1999; Ullman, 2004). According to this approach, past tense forms of regular verbs are constructed with the automatic application of a general rule, which instructs the addition of the $-e d$ suffix to the verb stem. Conversely, irregular past tense forms are directly retrieved from memory, as they occupy separate lexical entries than their stems. A different viewpoint is the one suggested by Rumelhart and McClelland (1986) who constructed a model which used phonological associations to produce the past tense of both regular and irregular verbs. After considerable training, the model was able to produce both regular and irregular past tense forms when the present tense forms were presented. Rumelhart and McClelland concluded that no rule-based processing takes place for the production of the regular past tense. Conversely, they suggested that all past tense forms, irrespective of their regularity, occupy separate entries in the mental lexicon than their stems and are retrieved as a result of their phonological association to the corresponding present tense forms (see also McClelland \& Patterson, 2002).

A significant number of studies on native speakers of English appear to support the dual-system model. One of the most influential studies has been the one by 
Marslen-Wilson \& Tyler (1997), who tested brain-damaged aphasic patients in an auditory priming task involving regular and irregular past tense forms. Marslen-Wilson and Tyler found that two patients had problems in processing irregular forms, while a third one had problems with regular forms only, and this difference corresponded to differences in the loci of the brain damage. This double dissociation was interpreted as indicative of the dual nature of past tense inflection in English, which also has neurological correlates (see also Longworth, Marslen-Wilson, Randall, \& Tyler, 2005; Miozzo, 2003; Tyler, Marslen-Wilson, \& Stamatakis, 2005; Tyler, Stamatakis, Post, Randall, \& Marslen-Wilson, 2005; Ullman, Pancheva, Love, Yee, Swinney, \& Hickok, 2005).

A lot of the supporting evidence for a dual system comes from studies utilising frequency effects: for example, Alegre and Gordon (1999) cite a number of studies that indicate that whereas irregular verbs consistently show frequency effects, in that more frequent forms are comprehended/produced faster than less frequent ones, such a pattern is not common in regular verbs. This has been interpreted as evidence that irregularly inflected forms are stored as full-form entries, with frequency being a crucial factor in their recognition, whereas regular forms are computed online, so frequency is only relevant for regular verbs of the highest frequency (Prado \& Ullman, 2009). ${ }^{1}$ Additional supporting evidence for the decompositional abilities of native speakers of English has recently been provided by Silva and Clahsen (2008). Silva and Clahsen conducted a masked-priming lexical decision study and revealed that regular stems (pray) are recognised faster if preceded by their inflected form (prayed) or an identical form (pray), compared to where preceded by an unrelated form (bake). This 
effect was interpreted as evidence that the inflected form was decomposed and allowed the stem to prime the target form, in the same way as the identical prime did.

Significant supporting evidence for the dual-system approach has also been provided by neuroimaging studies that used Event-Related Potentials (ERPs). In neuroimaging literature, distinct ERP effects have been shown to underlie different aspects of language processing. One of the most relevant ERP effects is the N400, i.e. a negativity that peaks $400 \mathrm{~ms}$. after the stimulus presentation. The N400 is considered to underlie lexical-semantic processing, and to be elicited upon processing of content words (Bornkessel-Schlesewsky \& Schlesewsky, 2009). As such, it has been shown to be modulated by word frequency (Kutas \& Federmeier, 2000), with less frequent words eliciting N400 effects with high amplitude; a similar effect is also observed upon encountering semantically unexpected words in a sentence environment (Kutas \& Federmeier, 2000).

The N400 effect has also been frequently linked to morphological processing. A study by Münte, Say, Clahsen, Schlitz, and Kutas (1999) used a delayed repetition priming task to investigate the priming effect that the inflected forms can have on the corresponding uninflected ones. The regular and irregular prime-target pairs were compared to unrelated pairs with the same targets. Although no significant RT effects appeared in either of the conditions, the regular pairs elicited an N400 ERP component on the target. The N400 has also been suggested to underlie the reactivation of a previously presented word stimulus (Chwilla, Brown, \& Hagoort, 1995). Thus, Münte and colleagues concluded that the regular prime created a memory trace capable of reactivating the representation of the stem when the target was encountered, something that did not happen with irregular primes. Münte et al. explained this by claiming that 
there is only one lexical entry for regular verbs, which was activated by the prime and was reactivated by the target, but two separate entries for irregular verbs, which did not prime each other. Similar effects were found by Newman, Ullman, Pancheva, Waligura and Neville (2007), who embedded present tense regulars and irregulars in sentences that called for past tense (e.g. beginning with yesterday). This syntactic violation elicited an N400 for regular verbs only, and they explained this effect by claiming that it is the absence of the regular affix that elicits this response. Further ERP evidence was presented by Allen, Badecker and Osterhout (2003). Allen et al. included grammatical and ungrammatical regular and irregular verbs with varied frequency (low versus high), which were embedded into sentences. Allen and colleagues focused on the differences in the delay of elicitation of P600, a component elicited when content words with contextually anomalous inflections are encountered (Rodriguez-Fornells, Clahsen, Lleó, Zaake, \& Münte, 2001). The results from this study revealed faster elicitation of the P600 component for grammatical violations with irregular verbs than with regular verbs. Allen and colleagues interpreted this effect by claiming that, whereas irregularly inflected verbs are accessed as whole-word forms which readily give clues about their syntactic role, regular verbs must first be morphologically parsed and decomposed for their role to be identified within the sentence. In sum, these effects suggest different processing for regular vs. irregular forms: regularly inflected verbs are decomposed online (Allen et al, 2003; Münte et al, 1999), and the past tense rule is automatically applied to regular forms (Newman et al., 2007). The same effects are not observed for irregular verbs, which are thought to be processed as non-decomposable whole words.

Apart from studies in English, there is also abundant behavioural information on processing of inflection from studies in other languages. In German for instance, a 
number of studies suggest that processing of inflection takes place via a dual system: Marcus, Brinkmann, Clahsen, Wiese, \& Pinker (1995) employed a judgement task in which the participants were presented visually with regularly and irregularly inflected participles embedded into sentences, and they had to rate those sentences for naturalness. Marcus et al. showed that, although in German regular verbs are less common than in English, still regularly inflected participles were preferred as the most natural and acceptable forms. Further behavioural findings were presented by Sonnenstuhl, Eisenbeiss and Clahsen (1999), who used the cross-modal priming paradigm in a lexical decision task on participles. Sonnenstuhl and colleagues showed that regular participles primed their present tense forms, and the priming effect was similar to the effect induced between identical words; additionally, this effect was not observed for irregular participles. In line with research in English, Sonnenstuhl et al. suggested that the same lexical entry is activated for both inflected and uninflected forms of a regular verb, whereas separate entries underlie the various forms of an irregular verb which are not morphologically related (see also Clahsen, Eisenbeiss, Hadler, \& Sonnenstuhl, 2001). Similar conclusions have been reached with the use of ERP (Penke, Weyerts, Gross, Zander, Münte, \& Clahsen, 1997) and fMRI techniques (Beretta, Campbell, Carr, Huang, Schmitt, Christianson, \& Cao, 2003) in German, but also behaviourally in Hebrew (Frost, Deutsch, \& Forster, 2000), Greek (Tsapkini, Jarema, \& Kehayia, 2002), Portuguese (Veríssimo \& Clahsen, 2009) and Hungarian (Lukacs \& Pléh, 1999). However, there are languages for which there is no evidence for dual-system processing: studies in Italian (Orsolini \& Marslen-Wilson, 1997), French (Meunier \& Marslen-Wilson, 2000), and Polish (Reid \& Marslen-Wilson, 2002) suggest a single mechanism for the processing of inflection. A possible explanation of 
this discrepancy is the suggestion that dual-system processing is language specific (Sonnenstuhl et al., 1999); the above languages are morphologically richer than the Germanic languages (English, German), and features such as conjugation (French, Spanish, Italian and Polish) and morphophonological alterations (Polish) introduce further morphological complexity to inflected forms. However, the aforementioned findings in other morphologically rich languages from various language families

(Greek, Hebrew, Portuguese, Hungarian) seriously weaken the suggestion about language-specificity due to morphological richness.

\section{Processing of inflection in a L2}

An important question in L2 processing research is whether or not L2 learners are able to reach the automated processing that underlies rule application in a L1. A number of factors have been suggested to affect the acquisition of an L2 (Grosjean, 1998; Johnson $\&$ Newport, 1989). For example, if the age of L2 acquisition is beyond a critical period of the individual's development, the automatisation of L2 grammar has been argued to be less successful (Bialystok, 1997; Butler \& Hakuta, 2004). Based on this idea, Ullman (2001a) presented an extension of his earlier Declarative/Procedural (DP) model (Ullman, 2001b) which concerned how L2 learners acquire grammatical rules, and how they compare to L1 learners. Ullman used neurocognitive data to claim that, if L2 is acquired later in life (and especially after childhood or puberty), rule usage should be gradually harder, and therefore restricted, for L2 learners. In terms of inflection, the model by Ullman predicts that the past tense rule will be absent in L2 learners. As a result, L2 learners should be incapable of decomposing regularly inflected forms into their constituents, but they should memorise them as separate lexical entries, similarly 
to irregular forms. However, Ullman later suggested that it is possible for L2 learners to have access to L2 language rules as an effect of increased L2 experience (Ullman, 2004).

Compared to L1 processing studies, L2 studies on on-line processing of regular inflection are rather scarce. One of the few studies investigating L2 processing of regular inflection is the study by Silva \& Clahsen (2008). Silva and Clahsen investigated the processing of regularly inflected forms by L2 learners using the masked priming technique. This method is widely accepted as a good means for detection of morphological relationships between words (Frost, Deutsch, Gilboa, Tannenbaum, \& Marslen-Wilson, 2000), and of whether regularly inflected forms of verbs prime the corresponding uninflected forms. Silva and Clahsen recruited advanced L2 learners of English from various language backgrounds (Chinese, Japanese, German) which were first exposed to English in a classroom setting at an average age of 11 years and had lived in the UK for 11 to 15 months. Comparison of the L2 data to those of native speakers revealed that native speakers were strongly primed by morphological prime-target pairs (prayed-pray) when compared to unrelated pairs (bake-pray), but L2 learners did not show any priming effects for morphological pairs. Additionally, both groups were facilitated by identical pairs (pray-pray). This finding suggests that, although the inflected primes were unconsciously processed by L2 learners, they did not prime the uninflected forms. This was interpreted to show that there was no morphological relationship between them. On the contrary, native speakers were affected by this relationship and were, therefore, primed. Silva and Clahsen suggested that the inability of L2 learners to decompose inflected forms arises 
from the absence of specific inflection-related structured representations from their grammar, which would allow them to morphologically parse an inflected form.

The above presented results are in contrast to the findings of a recent study on the processing of L2 inflection by Kirkici (2005). Kirkici employed a simple lexical decision task on regularly and irregularly inflected past tense forms of low and high frequency, in which high- and low-proficiency Turkish-English L2 learners with classroom L2 exposure took part. Although the results from the low-proficiency group were inconclusive, the high-proficiency group was overall slower in recognising regular past tense forms compared to irregular ones, suggesting that an additional process takes place for this type of verbs, namely decomposition. Kirkici (2005) failed to find any significant frequency effects on either regular or irregular verbs. The dual-system model predicts frequency effects for stored forms, namely that the highly frequent ones should be responded to more quickly. Kirkici explained the lack of a frequency effect based on L2 instruction, i.e., the use of irregular verb lists. According to Kirkici, the administration of irregular verb lists in a classroom setting does not take into account the actual frequency of the forms because all of them are expected to be memorised in a similar way. As a consequence, learning of irregular verbs through lists outstrips them from any frequency features.

Useful evidence for the decomposing abilities of L2 learners comes also from studies on other domains of inflectional morphology. Gor and Cook (2010) conducted a study on the processing of regularly and irregularly inflected infinitives in L2 Russian by highly proficient English-Russian learners. Gor and Cook employed an auditory priming lexical task where they presented their participants with regular, irregular and semi-regular verbs (the latter being a highly productive non-regular class with complex 
allomorphy). Each trial consisted of a word pair, including the first person singular as the prime and either the infinitive form or an unmatched word as the target. Gor and Cook reported priming effects for all verb categories and for both L2 learners and native speakers of Russian, with the irregular verbs yielding greater priming effects. They attributed these findings to the decomposition of the majority of the verbs they used (even some of the irregular ones), which is achieved by L2 learners too. Gor and Cook linked this high sensitivity to decomposition to the type of instruction that the L2 learners received, and suggested that written input leads to over-reliance to decompositional processing and prevents the formation of whole-word auditory representations. L2 decomposition of irregular forms with distinct suffixes is not a novel finding; it has also been demonstrated for late learners of German (Neubauer \& Clahsen, 2009) and Spanish (de Diego Balaguer, Sebastian-Galles, Diaz, \& RodriguezFornells, 2005). Additionally, L2 learners have been shown to be able to decompose regularly inflected nouns in Swedish (Lehtonen, Niska, Wande, Niemi, \& Laine, 2006; Portin, Lehtonen, \& Laine, 2007), especially low-frequency forms, but also to decompose real and pseudo-derivations (Diependaele, Duñabeitia, Morris, \& Keuleers, 2011).

To date, most studies investigating the processing of inflectional morphology in L2 learners have used tasks tapping processing at the single-word level. Paradis (2004) pointed out that the use of single-word tasks may be problematic for the study of language processing. This is because in normal language use, words appear in sentential contexts, and therefore, factors such as their syntactic and thematic role, as well as the pragmatic context, can affect how they are processed and interpreted. Results from single-word tasks may not reflect the way we process language in real life, 
but other processes, like memory retrieval. Paradis reviewed a number of neuroimaging studies on L1 and L2 speakers and noticed that differences in brain activation between the two populations are observed in sentence-level studies but not in word-level ones. He explained this finding by suggesting that isolated words are processed by both populations as lexical items; on the other hand, grammatical words provide morphosyntactic cues that are utilised only by L1 speakers for sentence comprehension, but L2 learners may still treat them as lexical items. Since the present study investigates application of a grammatical rule during online comprehension in L2, a more ecological sentence-level comprehension task was selected, which resembles more closely online language processing.

The only available study that has investigated $\mathrm{L} 2$ processing of inflection at the sentence level is by Hahne, Mueller and Clahsen (2006), and focused on L2 learners of German. Hahne et al. conducted an ERP experiment investigating the processing of inflectional violations. Hahne et al. recruited proficient L2 speakers of German (L1: Russian) who had lived in a German-speaking environment for 4.5 years on average and were first exposed to the L2 during adolescence. Following the design in Penke et al. (1997), Hahne et al. used four lists of German participles: regularly inflected, irregularly inflected, overregularised (where the regular inflectional suffix was attached to the stems of otherwise irregular verbs) and irregularised (where an irregular suffix replaced the regular one). These were embedded in plausible sentences, which the participants had to read. The ERP effects showed a clear distinction between the two types of morphological violations described above: regularised participles of irregular verbs elicited a LAN and a smaller P600 response when compared to correct irregular participles. The LAN response has been suggested to reflect violations of rule-based 
morphological processing (Penke et al., 1997), whereas the P600 response has been shown to relate to controlled processing and especially reanalysis (Friederici, 2002). The elicitation of these two responses suggests that participants made use of the rule, realised its misapplication to an irregular form, and conducted a reanalysis. On the other hand, a N400 was elicited upon encountering irregularisations of regular verbs. This has also been reported in native speakers for pronounceable non-words that are created by irregularisation, so it is likely related to lexical violations (Penke et al., 1997). Taken together, these two findings suggest that during sentence processing, L2 learners process regular and irregular verbs via two distinguishable routes, similarly to native speakers. This demonstrated that the dual-system model of processing applies to highly proficient L2 learners.

Based on these findings, Clahsen and Felser (2006) suggested that, although the complete rule system of a language is not available to L2 learners irrespective of their proficiency, there are a number of rules which are easier for them to automatise, including the regular inflection rule. In this sense, they extended the Ullman (2004) model by dissociating different types of rules: they suggested that it is the more complicated syntactic rules that are inaccessible, whereas the automatisation of the inflectional rules is possible, but it is subject to L2 learners' proficiency, practice, and exposure to their L2.

\section{L2 exposure effects}

L2 practice is closely related to L2 exposure. Muñoz (2008) describes two types of L2 exposure: Naturalistic, where learning takes place within the L2 environment, and Foreign (Classroom), where learning is through formal instruction in a structured way, 
without any other type of L2 input. The most notable difference between the two is that in naturalistic exposure, L2 input is unlimited and unstructured, whereas in classroom exposure the input is specific and sometimes restricted. Thus, practice seems to be qualitatively different in those two types, so it is possible that ultimate attainment would be different in each case. Flege (2009) reviewed several studies that examine the effects of naturalistic exposure, and suggested that extensive naturalistic exposure encompasses extensive L2 input, and this in turn may affect L2 acquisition. The effects of naturalistic exposure have been examined in several domains: in terms of phonological processing for example, Flege and Liu (2001) conducted a series of tests (identification of word-final English stops, grammatical sensitivity and listening comprehension), and revealed that L2 participants with extensive naturalistic exposure (4-15 years) performed better than participants with limited naturalistic exposure (up to 4 years).

Fewer studies have focused on the effects of naturalistic exposure on online L2 processing, and the available evidence is not conclusive. Frenck-Mestre (2002) investigated relative clause (RC) attachment preferences of advanced L2 learners on an eye-tracking study, and revealed significant effects of naturalistic exposure. Participants with naturalistic exposure of 5 years revealed native-like RC attachment preferences, while participants with very little naturalistic exposure ( 9 months) tended to transfer their L1 preferences and apply them to the L2. Similar effects were presented by Dussias (2003), who additionally revealed that L2 RC attachment preferences are not only successfully utilised by L2 learners, but can also be applied to their L1. Dussias suggested that exposure to a naturalistic environment affects processing strategies in 
L2, but can also have an impact on processing in the L1 (see also Dussias \& Sagarra, 2007).

Although the study of RC attachment has provided substantial evidence that naturalistic exposure can affect processing strategies in L2, it is possible that the influence on L2 processing is not across the board. For example, Pliatsikas and Marinis (under review) investigated processing of intermediate traces of wh-movement by L2 learners with and without naturalistic exposure to English, which were compared to native speakers. Processing of intermediate traces presupposes abstract structure-based sentence processing, which has been demonstrated for native speakers of English but not for L2 learners with minimal naturalistic exposure (Marinis, Roberts, Felser, \& Clahsen, 2005). Pliatsikas and Marinis revealed that even L2 learners with almost 7 years of naturalistic exposure to the L2 do not apply structure-based processing in L2, but instead resort to lexical and semantic information for the interpretation of the sentence.

In the domain of morphological processing, the effects of the type of exposure are relatively understudied. Gor and Long (2009) have underlined the effects of classroom exposure in the acquisition and processing of inflection in L2. According to Gor and Long, classroom exposure can be beneficial for the acquisition of forms of low frequency or for the establishment of regular inflectional patterns, as classroom exposure is independent of naturalistic frequencies that guide learning in a naturalistic environment. This suggestion is only partially in accordance with the suggestions by Ullman (2004) and Clahsen and Felser (2006), who claimed that automatisation of rule processing may be dependent on factors, such as type and amount of L2 exposure, which, however, they do not specify or quantify. Therefore, the question of what kind 
and amount of exposure is needed for the establishment of regular inflectional patterns remains open. To address the issue of exposure effects on L2 processing of past tense inflection, the present study focuses on processing of inflected forms embedded in wellformed sentences by L2 learners with different types of L2 exposure.

\section{This study}

The purpose of this study was to investigate the way L2 learners process regular and irregular English past tense inflection at the sentence level. This was studied with the use of real forms (regular, irregular) and forms that include violations (regularised, irregularised). The L2 learners had Greek as their L1. Greek is a highly inflected language, in which regular and irregular past tense inflection is carried out with simple suffixing or with suffixing and prefixing of the verb stem. Irregular inflection is manifested as stem allomorphy, which nevertheless bears the same prefixes/suffixes with regular verbs. Therefore, both regular and irregular verbs have a similar high degree of orthographic overlap between the present and the past tense forms (Tsapkini, Jarema \& Kehayia, 2002).

If the use of a dual system is available to L2 learners, it is possible that the differences reported by Hahne et al. (2006) will also be found in processing English as an L2 at the sentence level. More specifically, and based on the findings by Kirkici (2005), processing of regularly inflected forms will yield significantly longer RTs than processing of irregularly inflected forms, and this is because of the additional process of decomposition that applies to the former. A difference in RTs is also expected between regularised and irregularised forms; if decomposition is achievable for every word-form that consists of valid morphemes (Diependaele et al., 2011), then evidence 
for decomposition should be found for regularised forms, with RTs similar to those of the regular forms. Irregularised forms on the other hand should be treated as non-words, and as such, they are expected to yield longer RTs.

Furthermore, to investigate to what extent naturalistic exposure is crucial for the automatisation of the regular inflection rule, the L2 learners were split into two groups of similar language abilities but with different type of L2 exposure: Naturalistic (NE) and Classroom (CE) exposure groups. Following the findings by Hahne et al. (2006), if naturalistic exposure plays a crucial role for L2 processing, we predict that the NE group should have established a dual system for past tense processing, and therefore, would process irregular verbs faster than regular ones. For the non-words, dual-system processing would result in the decomposable regularised forms being processed faster than the irregularised ones which are non-words. If naturalistic exposure is necessary for the processing of rules in the L2, then the CE group should reveal no processing differences between regular and irregular verbs, but also between regularised and irregularised ones. This would indicate the lack of decomposition for this group. Conversely, if classroom exposure can also lead to native-like processing of L2 rules, then the CE group should be similar to the NE group.

\section{Method}

\section{Participants}

Two groups of highly-proficient Greek-English L2 learners participated in this study:

30 with naturalistic exposure to an English-speaking environment (NE, mean age: 29, SD: 3.99, range: 20-38) and 30 with classroom exposure to English (CE, mean age 27, 
SD: 4.99, range: 16-35). Additionally, a group of 30 English Native speakers (NS, mean age: 20, SD: 3.86, range: 18-40) served as the control group. Both L2 groups reported English as the non-native language they spoke the best. The NS and NE groups were tested in the UK, while the CE group was tested in Greece. The L2 participants were assessed for their competency in English with the Quick Placement Test (QPT) (UCLES, 2001). The QPT provides 20-minute computer-based language tests that assess comprehension skills in English. The participants' results were presented by the software on a scale from 1 to 5 and only participants who scored in ranks 4 (Effective proficiency) and 5 (Mastery) were invited to participate in the experimental task. The NE group scored 83.97\% (range: 68-100\%, SD: 8.05), while the CE group scored $76.8 \%$ (range: $65-91 \%$, SD: 7.75). A one-way ANOVA revealed that this difference was significant $[F(1,58)=12.338, \mathrm{p}<0.001]$.

Participants' language background was assessed through a questionnaire, administered at the beginning of the session. The NE group candidates were initially required to confirm that they had lived and worked in an English-speaking country for at least one year immediately prior to this study. Similarly, the CE group candidates were excluded if they had lived in an English-speaking country for over a month. The questionnaire also included questions related to the participants' language environment and experiences, including the amount of each language they speak daily. This enabled us to build the sample's language profile and investigate whether any particular aspects of it can influence the participants' performance. It has been suggested that self ratings provides a good indicator of the learner's language abilities in an L2 (MacIntyre, Noels, \& Clément, 1997). Therefore, in the same questionnaire, the participants were asked to rate their speaking, writing, listening, and reading skills in English on a 1-6 scale 
( $1=$ poor, $6=$ native). The results of the questionnaire and the participants' languagerelated biographical data are illustrated in Table 1:

Please insert Table 1 around here

Table 1 shows that the NE group uses English in everyday life significantly more often than the $\mathrm{CE}$ group does and the opposite occurs for the use of Greek. Moreover, the groups did not differ in the age of L2 onset or the years they had been studying English as an L2. The participants of the NE group rated themselves higher than the CE group for their production skills as well as for writing and listening, but not for reading. The absence of a significant between-groups difference in self-rating for reading, the skill of interest in our task, suggests that the two groups have equal reading abilities.

\section{Materials}

120 English verbs were used in the self-paced reading (SPR) task, 60 regulars and 60 irregulars. The irregular verbs were selected so as to represent the majority of the irregular families described by Pinker (1999) and no modal or auxiliary verbs were used. The two verb lists were subsequently divided into two sub-lists each, in order to create the four conditions of the experiment, based on the task employed by Hahne et al. (2006). 30 regular verbs and 30 irregular verbs were inflected in the past tense. The remaining 30 regular verbs, which were selected based on their form similarity to irregular verbs (e.g. show-throw, reach-teach), were irregularised in the past tense, i.e. irregular-like past tense forms were created in order to resemble real irregular forms. For the irregularisation, the irregular templates described by Pinker (1999) were 
applied, and the irregularised forms were created as closely as possible according to the phonology and morphology of real irregular forms (e.g. reach-raught, according to teach-taught). Any irregularised form that resembled an existing and meaningful word was excluded. Similarly, the 30 remaining irregular verbs were affixed with the regular -ed morpheme to create regularised forms. The -ed was directly affixed to the regular verb stem and no morphological or phonological alteration of the standard irregular form was preserved (e.g. eat-eated).

Three important factors were controlled for during the compilation of the verb lists for this study: frequency of occurrence, the number of orthographic neighbours the verbs had (neighbourhood density), and length. Care was taken so that only verbs that feature high frequency of occurrence were selected, because a verb of low frequency may be unknown to the L2 learner; in addition, the frequency of a verb can influence how easily it is learnt (Bybee \& Slobin, 1982), and it has been proven crucial for the processing of past tense inflection (Alegre \& Gordon, 1999). The verbs' frequency of occurrence was assessed using the CELEX database (Baayen, Piepenbrock, \& Gulikers, 1995), where for each word form the frequency of occurrence per million of written words in the COBUILD corpus was extracted, expressed as a logarithmic value. Orthographic neighbourhood density has been defined as "the number of other words of the same length that share all but one letter in the same position" (Grainger, Muneaux, Farioli, \& Ziegler, 2005). Orthographic neighbourhood density has been shown to affect visual word recognition (Frost et al., 2000), so it is important that it is controlled for studies such as the present. The orthographic neighbourhood density data were extracted using the English Lexicon Project Database (ELP) (Balota, Yap, Cortese, Hutchison, Kessler, Loftis, Neely, Nelson, Simpson, \& Treiman, 2007). Finally, the 
length of the items in each of the four lists was controlled, because this could affect the reading time of the words. To ensure that those four base form lists were of comparable properties, one-way ANOVAs for length, frequency, and neighbourhood density were conducted, with Verb type as the independent factor (Regular, Irregular, Regularised, Irregularised). The ANOVAs revealed no main effects of Verb type for length [F $\left.(3,116)=0.492, p=0.69, \eta^{2}=0.013\right]$, frequency $\left[F(3,116)=1.376, p=0.25, \eta^{2}=\right.$ $0.034]$ or neighbourhood density $\left[F(3,116)=1.322, p=0.27, \eta^{2}=0.033\right]$ of the base forms ${ }^{2}$.

The same ANOVAs were conducted for the four lists of the inflected forms, which were the critical segments of this experiment. These analyses can be found in Table 2, while all the experimental items, along with their length, frequency, and neighbourhood density data, can be found in Tables $5 \& 6$ in the Appendix.

Please insert Table 2 around here

The regularly and irregularly inflected forms did not differ in terms of frequency $\left[F(1,58)=0,051, p=0.822, \eta^{2}=0.001\right]$. Being non-words, the regularised and irregularised forms were only compared to the real words in terms of length and neighbourhood density. The analysis showed no significant differences in terms of neighbourhood density $\left[F(3,116)=1.395, p=0.48, \eta^{2}=0.035\right]$, whereas the analysis of length revealed a main effect of Verb type $\left[F(3,116)=11,229, p<0.01, \eta^{2}=0.225\right]$. A post hoc analysis revealed that regular forms were significantly longer than irregular 
$(\mathrm{p}=0.007)$ and irregularised forms $(\mathrm{p}<0.001)$, and also that regularised forms were longer than both irregular $(\mathrm{p}=0.001)$ and irregularised forms $(\mathrm{p}<0.01)$. This difference can be readily attributed to the presence of the -ed affix on the regular and regularised forms, and this assumption is reinforced by the absence of a significant difference in length between regular and regularised forms. ${ }^{3}$

The above described inflected and pseudo-inflected forms were subsequently embedded in one sentence each. 120 plausible and syntactically simple experimental sentences were constructed, along with 80 filler sentences, and 10 practice items, making the number of sentences 210 in total. The sentences of the SPR task were divided into 6 segments, as shown in the examples below.

Regular: The head teacher / gave a prize / to the student because she / helped / a poor guy / last month.

Irregular: The enemies / were scared by / our soldiers who / fought / very bravely / and won the battle.

Regularised: Aunt Tina / felt really sad / when her husband / taked / his stuff / and left home.

Irregularised: The babysitter / was so scared / by the noise that she / drep / the plate / with the baby food.

In the experimental sentences, the verb was always in Segment 4 (critical segment). Apart from the critical segment, which was controlled for length and word frequency, the rest of the sentence was constructed and segmented without following a particular pattern to ensure that participants would not be able to make predictions based on 
structure similarity between the sentences. $45 \%$ of the experimental sentences and all of the fillers were followed by a comprehension question. This ensured that participants read the sentences for comprehension, but also provided us with information as to how good the participants comprehended the sentences and also acted as a distracting task.

\section{Procedure}

The participants were scheduled for an hourly slot each. In the case of L2 learners, the language background questionnaire was completed first, and then the QPT was administered. Participants who ranked 4 or 5 in the QPT, proceeded immediately with the SPR task. The SPR task was designed and presented on the E-prime experimental software (Schneider, Eschman, \& Zuccolotto, 2002a; 2002b), which was also tuned to collect accuracy data from the questions and response times from each segment according to the noncumulative moving-window procedure (Just, Carpenter, \& Woolley, 1982; Marinis, 2003). The sentences were presented in a segment-by-segment fashion in white letters (Courier new, $18 \mathrm{pt}$ ) on black background in the centre of a 14inch CRT monitor (Resolution: 800x600, colour depth: 16-bit, refresh rate: 60Hz). Participants used an E-prime compatible 5-button Serial Response Box with three active buttons: one pacing button, and two response buttons.

Prior to the experiment, the participants were presented with oral and written instructions and were given the opportunity to ask questions about the experiment. A practice session was subsequently initiated, followed by the actual experiment. They were instructed to read each segment as quickly as possible for comprehension and then to press the pacing button to move to the next segment. Comprehension questions appeared immediately after the last segment of the sentence on the same screen with 
two potential answers, one at bottom right and one at bottom left. One response button was assigned to the left answers and one to the right answers, and the participants were instructed to press the button corresponding to the correct answer. For half of the questions, the correct answer was on the right, and for the other half it was on the left. The total duration of this experiment was approximately 35 minutes.

\section{Results}

\section{Accuracy}

All three groups were highly accurate in answering the comprehension questions that followed the experimental sentences, as shown in Table 3.

Please insert Table 3 around here

One-way ANOVAs revealed no significant between-group differences in accuracy for the sentences with Regular $[F(2,87)=0.090, p=0.914]$, Irregular $[F(2,87)=0.065, p=$ 0.937], Regularised $[F(2,87)=1.295, \mathrm{p}=0.279]$, and Irregularised verbs $[\mathrm{F}(2,87)=0.203$, $p=0.817]^{4}$. The trials with incorrect answers were excluded from further analyses.

\section{Reading times}

RTs were collected from all segments and questions. The RTs from all groups were screened for extreme values, defined as any RT that exceeded $4000 \mathrm{~ms}^{5}$. This affected $0.99 \%$ of the NS group data, $0.90 \%$ of the NE group data, and $1.03 \%$ of the CE group data. Additionally, the data were screened for outliers defined as RTs beyond two 
standard deviations from the mean RT for each condition per subject and per item. This affected $4.88 \%$ of the NS group data, $5.73 \%$ of the NE group data, and $5.95 \%$ of the CE group data. Extreme values and outliers were replaced by the subject or item mean RT per condition.

For the aims of this experiment, RTs from three segments were analysed: Segment 4, the critical segment, and Segments 3 and 5, in order to investigate for any potential spill-over effects to and from Segment 4, respectively. Table 4 shows the mean RTs for each group per segment per condition.

Please insert Table 4 around here

A mixed two-way repeated measures ANOVA was conducted for each segment, with Group (NS, NE and CE) as a between groups factor and Verb type (Regular, Irregular, Regularised, Irregularised) as a within groups factor. Interactions were followed up with one-way ANOVAs for each condition to address between group differences and repeated measures ANOVAs for each group separately to address differences between the conditions for each group separately.

\section{Segment 3}

Segment 3 is the segment immediately before the verb which is the critical segment, and was analysed to rule out that effects at Segment 4 were caused by effects at Segment 3.

The mixed ANOVA revealed a main effect of Group $[\mathrm{F}(2,87)=18.279$, $\mathrm{p}<$ $\left.0.001, \eta^{2}=0.296\right]$, a main effect of Verb Type $\left[F(3,261)=111.539, p<0.001, \eta^{2}=\right.$ 
0.562], and a Group x Verb Type interaction $\left[F(6,261)=3.858, p<0.001, \eta^{2}=0.081\right]$. In all conditions, there were significant differences between the groups: Regulars $\left[F(2,87)=15.101, p<0.001, \eta^{2}=0.258\right]$, Irregulars $\left[F(2,87)=21.132, p<0.001, \eta^{2}=\right.$ 0.327], Regularised $\left[F(2,87)=17.071, p<0.001, \eta^{2}=0.282\right]$, and Irregularised $\left[\mathrm{F}(2,87)=12.684, \mathrm{p}<0.001, \eta^{2}=0.226\right]$. This was because both groups of $\mathrm{L} 2$ learners showed longer RTs than the native speakers in all conditions (all comparisons $\mathrm{p}<$ 0.001). The within group analyses showed a similar pattern in the three groups. In all groups, the condition with the Regular verbs showed longer RTs than the condition with Regularised (NS: $\mathrm{p}=0.005$; NE: $\mathrm{p}=0.026$; CE: $\mathrm{p}=0.005$ ) and Irregularised verbs (all groups: $\mathrm{p}<0.001)$. The condition with Irregulars showed longer RTs than the conditions with Regularised (NS: $\mathrm{p}=0.006$; NE: $\mathrm{p}<0.001$; CE: $\mathrm{p}<0.001$ ) and Irregularised verbs (all groups: $\mathrm{p}<0.001$ ), and they also showed longer RTs in the condition with Regularised than in Irregularised verbs (NS: $\mathrm{p}=0.002$; NE: $\mathrm{p}<0.001$; CE: $p<0.001)$. There were no significant differences between the conditions with Regulars and Irregulars in any of the three groups (NS: $p=1.0$; NE: $p=0.5$, CE: $p=$ 1.0). The observed Verb Type $x$ Group interaction is likely to have resulted from differences at the significance levels of the within-groups comparisons between the groups.

\section{Segment 4}

Segment 4 is the critical segment and consists of the regular, irregular, regularised, or irregularised verb. The mixed ANOVA revealed a near-significant effect of Group $\left[\mathrm{F}(2,87)=3.071, \mathrm{p}=0.051, \eta^{2}=0.066\right]$, an effect of Verb Type $[\mathrm{F}(2.272,197.638)=$

$\left.66.755, \mathrm{p}<0.001, \eta^{2}=0.434\right]$, and a Group x Verb Type interaction $[\mathrm{F}(4.543,197.638)$ 
$\left.=3.341, p=0.008, \eta^{2}=0.071\right]$. The one-way ANOVAs revealed significant betweengroup differences for Irregulars $\left[\mathrm{F}(2,87)=3.446, \mathrm{p}=0.036, \eta^{2}=0.073\right]$ and Regularised verbs $\left[F(2,87)=6.940, p=0.002, \eta^{2}=0.138\right]$. Post hoc analyses showed that for Irregulars, the NE group showed longer RTs than the CE group $(p=0.047)$, and that for Regularized verbs the NE group showed longer RTs than both the NS group (p $=0.002)$, and the CE group $(\mathrm{p}=0.024)$. No other significant differences were observed.

The within group analyses showed a main effect of Verb Type in all groups $\left[\mathrm{NS}: \mathrm{F}(2.035,59.012)=29.304, \mathrm{p}<0.001, \eta^{2}=0.503 ; \mathrm{NE}: \mathrm{F}(2.344,67.989)=19.710\right.$, $\mathrm{p}<0.001, \eta^{2}=0.405$; CE: $\left.\mathrm{F}(2.031,58.885)=27.630, \mathrm{p}<0.001, \eta^{2}=0.488\right]$, but the subsequent pair-wise comparisons with Bonferroni correction showed some differences between the groups causing the Group x Verb Type interaction. All groups showed longer RTs in Regulars than Irregulars (all groups: $\mathrm{p} \leq 0.001$ ) and shorter RTs for Regulars than for Irregularised verbs (all groups: $\mathrm{p}<0.01$ ). All groups also showed shorter RTs in Irregulars than in Regularised (all groups: $\mathrm{p} \leq 0.010$ ) and Irregularised verbs (all groups: $\mathrm{p}<0.001$ ). The NE group showed shorter RTs for Regulars than Irregularised verbs $(\mathrm{p}=0.005)$, which was not significant in the other groups; the NS and CE groups showed shorter RTs in Regularised than in Irregularised verbs (NS: p < 0.001; CE: $p=0.029$ ), but there was no significant difference between those verb types in the NE group. Finally, the different pattern of performance between Segments 3 and 4 in all comparisons and for all groups indicates that there were no spill-over effects from Segment 3 to Segment 4.

To investigate whether the significant difference in RTs between the four verb types reflected differences in length between the verb types, we ran a simple linear regression analysis on the mean RTs per item across all groups, in which length was 
added as the predicting variable. The results of the regression indicated that length did not explain a proportion of variance in the mean $\mathrm{RT}$ of the verbs $\left[\mathrm{R}^{2}=0.024, \mathrm{~F}(1,118)\right.$ $=2.859, \mathrm{p}=0.093]$, and that it did not significantly predict the mean RTs $[\beta=9.857, \mathrm{t}$ $(118)=1.691, p=0.093]$. Finally, if length was crucial, we would also expect to find longer RTs for Regularised vs. Irregularised forms because Regularised forms were longer than Irregularised ones, but this was not evident in any of the groups.

\section{Segment 5}

The mixed ANOVA revealed a main effect of $\operatorname{Group}\left[F(2,87)=6.076, p=0.003, \eta^{2}=\right.$ 0.123], a main effect of Verb Type $\left[F(2.473,215.143)=200.1, p<0.001, \eta^{2}=0.697\right]$, and a significant Group x Verb Type interaction $[\mathrm{F}(4.946,215.143)=3.709, \mathrm{p}=0.003$, $\left.\eta^{2}=0.079\right]$. The one-way ANOVA revealed significant between-groups differences for Regulars $\left[F(2,87)=5.165, p=0.008, \eta^{2}=0.106\right]$, Irregulars $[F(2,87)=5.332, p=$ 0.007, $\left.\eta^{2}=0.109\right]$, Regularised $\left[\mathrm{F}(2,87)=8.096, \mathrm{p}=0.001, \eta^{2}=0.157\right]$, and Irregularised verbs $\left[F(2,87)=3.957, p=0.023, \eta^{2}=0.083\right]$. Post hoc analyses revealed that the NS group showed shorter RTs than the NE group for Regulars $(p=0.007)$, Irregulars $(p=0.009)$, and Regularised verbs $(p<0.001)$. The NS group showed shorter RTs than the CE group in Irregulars $(p=0.035)$, Regularised $(p=0.036)$, and Irregularised verbs $(\mathrm{p}=0.031)$.

The within group analyses showed a main effect of Verb Type in all groups $\left[\mathrm{NS}: \mathrm{F}(3,87)=77.416, \mathrm{p}<0.001, \eta^{2}=0.727 ; \mathrm{NE}: \mathrm{F}(2.032,58.914)=62.946, \mathrm{p}<\right.$ 0.001, $\left.\eta^{2}=0.685 ; \mathrm{CE}: \mathrm{F}(3,87)=71.446, \mathrm{p}<0.001, \eta^{2}=0.711\right]$ and the subsequent pair-wise comparisons with Bonferroni correction showed similar results for most 
comparisons. All three groups showed longer RTs for Regulars than Irregulars (all groups: $\mathrm{p} \leq 0.001$ ) and shorter RTs in Regulars than in Regularised (all groups: $\mathrm{p}<$ 0.001) and Irregularised verbs (all groups: $\mathrm{p}<0.001$ ). All groups also showed shorter RTs in Irregulars than in Regularised (all groups: $\mathrm{p}<0.001$ ) and Irregularised verbs (all groups: $\mathrm{p}<0.001)$. However, only the group of NS and CE showed shorter RTs in Regularised than in Irregularised verbs (NS: $p=0.007$ CE: $p=0.05$ ), which has caused the Group x Verb Types interaction. The similarity of the effects to those of Segment 4 suggests a spill-over effect from Segment 4 to Segment 5 for all groups.

\section{Relation between proficiency level, accuracy and RTs}

To investigate a possible relationship between proficiency level and the participants' performance in our task, we conducted Pearson correlations between the participants' proficiency level and their accuracy and RTs. These showed that the proficiency of the NE group was not correlated to the mean accuracy $(\mathrm{p}=0.956)$, the mean RT at the critical segment $(p=0.404)$, or the mean RT of a whole sentence $(p=0.543)$. Similarly, the proficiency of the CE group was not correlated to mean accuracy ( $p=0.187$ ), mean RT at the critical segment $(p=0.703)$, or mean RT of the whole sentence $(p=0.658)$.

\section{Discussion}

The present study investigated the processing of English regular and irregular verb morphology at the sentence level in highly proficient Greek L2 learners of English and whether this is influenced by the type of exposure in the L2. The main results can be summarised as follows: first, regularly inflected verbs were processed more slowly than irregular verbs during online processing of grammatical sentences by native speakers. 
Second, this effect was also observed in late learners of English with high proficiency. Third, this difference was not dependent on the type of language exposure of the L2 learners. Fourth, small differences in proficiency level among highly proficient L2 learners did not affect their accuracy and RTs.

\section{L1 processing of past tense inflection}

Our results revealed a clear distinction between processing regular versus irregular past tense forms of English verbs also reported in several other studies (Allen et al., 2003; Newman et al., 2007). Having controlled for possible confounding factors of the two verb lists (such as frequency, neighbourhood density, and length), we can attribute this distinction to the morphological difference between the two verb types. The delay for regular verb processing can be explained by the activation of the regular rule, which automatically leads to the decomposition of the inflected form (Kirkici, 2005). Conversely, irregular past tense forms already exist in the mental lexicon as separate entries, so no computational processes are required, which can explain the apparent facilitation in their RTs. Consequently, our findings support the dual-system theory (Pinker, 1999) and challenge the Parallel Distributed Model (Rumelhart \& McClelland, 1986), according to which there should not be any differences in comprehension speed between the two lists, as regularity plays no important role. These findings appear to suggest that past tense processing takes place according to the DP model (Ullman 2004), with the irregular verbs relying on direct retrieval from declarative memory and the regular verbs relying on decomposition according to the -ed rule, which is suggested to be carried out by the procedural memory system. 
Additional evidence in favour of decomposition is provided by processing of regularised and irregularised verbs. Our results reveal a greater processing cost for irregularised forms (e.g. raught) than regularised ones (e.g. feeled), but also no difference between regular and regularised forms. This difference could be due to the presence of the regular suffix on the regularised forms; although these forms are incorrect, the individuals are able to process them in a decompositional manner. Those results indicate that the decomposing mechanism could be activated in the presence of a valid recognisable morpheme, such as -ed, and a valid stem (Diependaele et al., 2011; Rastle, Davis, \& New, 2004; Rastle \& Davis, 2003). On the other hand, by being nonwords, the irregularised forms are processed more slowly than the other verb types (also in Münte et al., 1999).

\section{L2 processing of past tense inflection}

The second important finding of this study is that highly proficient L2 learners of English show the same effects with native speakers. Indeed, the longer RTs observed for regularly inflected forms, as compared to irregularly inflected ones, suggest activation of a rule-based decomposition mechanism. This finding is not in accordance with the results reported by Silva \& Clahsen (2008) who found that regular verb stems were not primed by inflected past tense forms. Silva \& Clahsen interpreted their findings to show that inflected forms are processed as full forms rather than composed ones. Although Silva \& Clahsen compared morphological primes to identical ones (i.e. prayed-pray vs. pray-pray), they did not compare regular vs. irregular verbs. Moreover, the fact that that study used masked priming with single words does not make this study directly comparable. Paradis (2004) suggested that single word studies are not the most 
appropriate to capture real language processing, because in real life words do not usually appear in isolation. According to that view, studies like Hahne et al. (2006) and the present are more capable of revealing the nature of past tense processing by L2 learners.

Our findings support the suggestion by Clahsen and Felser (2006) that, although native-like rule processing is difficult and potentially unachievable by L2 learners, there are a number of rules than can be automatised and actively utilised in L2 processing, one of them being the regular past tense rule. Indeed, our findings suggest that not only L2 learners have an internal representation of the past tense rule, but also that their processing is comparable to that of native speakers of English. Moreover, the present results confirm Ullman's suggestion (2004) that L2 inflectional rules can be acquired as a function of L2 experience, and this experience does not have to be in a naturalistic environment, but can be limited to a highly-structured classroom environment (Gor \& Long, 2009). It seems that regular past tense inflection is among those rules that are available for automatisation, at least by highly proficient L2 learners (Kirkici, 2005).

Non-word processing data by the two L2 groups are less conclusive. The CE group showed a similar pattern of effects to the NS group: irregularised forms had the longest RTs, and regularised forms had longer RTs than irregular ones. One important difference between the CE and the NS groups, however, was that the CE group revealed longer RTs for the regularised forms, compared to the regular ones, whereas NSs did not show a significant difference between these two verb types. The increased RTs for the regularised forms may be due to the participants' being non-native speakers, and therefore slower in reading a non-word that appears in a potentially 
correct grammatical form (valid stem, valid affix). This is also illustrated more dramatically in the results from the NE group, in which the regularised verbs had longer RTs than both regulars and irregulars, but with no difference to the irregularised ones. Therefore, the L2 learners' performance in the non-words does not provide clear evidence for or against the decomposing abilities of L2 learners, although results from the CE group indicate a discrepancy in processing the two types of non-words.

\section{Effects of L2 exposure, proficiency and age of onset}

Our L2 groups differed in terms of type of L2 exposure, one of them having only classroom exposure and the other one having an average of 6.5 years naturalistic exposure. This distinction was initially made in order to investigate the possible influence of naturalistic L2 exposure on language skills, given that according to Ullman (2004) substantial experience in L2 can lead to more automated use of a number of L2 rules. The results suggest that the type of L2 exposure is not an important factor that facilitates the automatisation of the past tense rule. Both L2 groups showed similar effects when real verbs were considered, with small variations regarding the processing of regularised verbs.

It could be argued that consolidation of the past tense rule requires a certain amount of L2 exposure, which is not confined to naturalistic exposure only. Indeed, both L2 groups in this study had studied English in a classroom environment for a mean of 8.5 years and started at a mean age of $8-9$ years. It is possible that several years of language education can assist in the automatisation of some language rules in L2, such as the past tense rule. Furthermore, although people in Greece do not usually speak or write in English in their everyday life, there is a considerable amount of exposure to 
English, mainly through popular culture. Apart from the extensive use of English websites and the popularity of English music, English-speaking movies are never dubbed but they are subtitled. Therefore, a substantial exposure to the language is present, and that may influence the way Greek-English L2 learners process English.

Although there was no difference between the two groups of learners in the processing of real verbs, we found a between-groups difference on the processing of non-words. This difference may be related to the type exposure. According to Gor and Long (2009) the structured nature of classroom exposure means that classroom learners are not affected by naturalistic frequencies, whereas naturalistic learners are primarily exposed to high-frequency forms and inflections. This suggests that, while both groups can freely and successfully process decomposable forms, classroom learners readily decompose forms with zero frequency, such as regularised forms, based on instructionbased probabilities of inflectional patterns. On the other hand, naturalistic exposure learners are affected by the zero frequency of the regularised forms, so the linguistic rule is not applied and these forms are processed similarly to irregularised forms, i.e. as non-decomposable non-words (c.f. Gor and Long, 2009, for similar experimental findings in L2 Russian). Thus, the observed between-group difference may have been caused by the NE learners' sensitivity to the frequency of the pseudo-inflected forms ${ }^{6}$.

Since we did not find a between-group difference in the processing of past tense of real words that is directly attributable to the type of language exposure, all highly proficient L2 learners are likely to be able to employ the past tense rule automatically. Despite the fact that the NE group scored higher in the language test, both groups were of high proficiency, and the proficiency level was not found to affect their performance. Although a direct comparison to participants with low proficiency was not carried out 
in this study, Kirkici (2005) showed that it is difficult to describe morphological processing of low proficiency L2 learners, as their performance can be constrained simply by their restricted L 2 competence. Therefore, it could be argued that a certain level of proficiency can accommodate some aspects of native-like rule-based L2 processing, at least some "shallow" morphological rules as described by Clahsen and Felser (2006), among which is the past tense rule (see also Hopp, 2010) ${ }^{7}$.

If increased level of proficiency accounts for the automatic processing of the past tense rule, then an explanation is needed for the discrepancy between the results of the present study and the study by Silva and Clahsen (2008). A critical point that could explain this discrepancy relates to the proficiency of the groups tested in the Silva and Clahsen study vs. the proficiency level of the participants in our study. In Silva \& Clahsen, L2 participants in Experiment 1 scored highly in the proficiency test, but participants in Experiment 2, which was conducted in order to control for methodological issues arisen from Experiment 1, were of medium-to-high proficiency; additionally, the participants' proficiency was drawn from their scores in the IELTS certificate, which did not necessarily reflect their language competence at the time of testing. Since participants in the present study were of advanced proficiency, it could be argued that advanced proficiency is beneficial for the acquisition and automatisation of the -ed rule in L2 learners. An additional important difference between the two studies concerns the age of onset: in the present study both groups started studying English at a mean age of 8-9 years, but in the Silva and Clahsen study all groups reported age of onset of a minimum of 12 years. Therefore, the present findings suggest that learning an L2 at the age of 8 can be beneficial for the automatisation of some language rules, as the procedural system involved in language processing may be more receptive to new 
information, and therefore controlled processes can become more easily automated. It may also be that the combination of an early age of onset and an increased amount of L2 exposure leads to the automatisation of those rules (Muñoz, 2008); indeed, the Silva and Clahsen groups have a mean age of 25 years and a mean age of onset of 13 years, which gives a mean overall exposure to English of 12 years. The corresponding figure for both groups in the present study was almost 20 years. However, this assumption does not necessarily account for the results presented by Hahne et al. (2006), as their participants had an age of onset of 17 years.

To conclude, the present findings suggest that establishment of L2 rule-based usage is depended on the interaction of a number of factors. While a high level of proficiency is essential for the successful consolidation of the past tense rule, the amount of overall exposure and the age of onset are also important. Consequently, it is the combination of all those factors that allowed our participants to treat regularly inflected forms similarly to native speakers of English. The observed distinction between processing regular and irregular past tense forms suggests that dual-system processing is accessible to both native speakers and L2 learners of English, and that the consolidation of the past tense rule is not related to the type but to the overall amount of L2 exposure.

Our study is the first to test effects of type of exposure in L2 processing of inflection. To address the effect of type of exposure, we controlled for the level of proficiency, the age of onset, and the L1 of the learners. To disentangle these factors, future studies need to manipulate also the level of proficiency, the length of exposure, the age of onset, and the L1-L2 combination. This can address the way these factors 
interact with each other and the relative contribution of each factor for the L2 processing of past tense inflection. 
Appendix: List of critical items with balancing data

Please insert Table 5 around here

Please insert Table 6 around here 
Acknowledgments (to be added later) 


\section{References}

Alegre, M., \& Gordon, P. (1999). Frequency effects and the representational status of regular inflections. Journal of Memory and Language, 40, 41-61.

Allen, M., Badecker, W., \& Osterhout, L. (2003). Morphological analysis in sentence processing: An ERP study. Language and Cognitive Processes, 18(4), 405 430.

Baayen, R. H., Piepenbrock, R., \& Gulikers, L. (1995). The CELEX Lexical Database (CD-ROM) (Version 2.5 (English)). Philadelphia: Linguistic Data Consortium, University of Pennsylvania.

Balota, D. A., Yap, M. J., Cortese, M. J., Hutchison, K. A., Kessler, B., Loftis, B., et al. (2007). The English Lexicon Project. . Behavior Research Methods, 39, 445459.

Beretta, A., Campbell, C., Carr, T. H., Huang, J., Schmitt, L. M., Christianson, K., et al. (2003). An ER-fMRI investigation of morphological inflection in German reveals that the brain makes a distinction between regular and irregular forms. Brain and Language, 85(1), 67-92.

Bialystok, E. (1997). The structure of age: in search of barriers to second language acquisition. Second Language Research, 13(2), 116-137.

Bornkessel-Schlesewsky, I., \& Schlesewsky, M. (2009). Processing Syntax and Morphology: A neurocognitive perspective. Oxford: Oxford University Press.

Butler, Y. G., \& Hakuta, K. (2004). Bilingualism and second language acquisition. In T. K. Bathia \& W. C. Ritchie (Eds.), The Hanbook of Bilingualism (pp. 114144). Malden: Blackwell. 
Bybee, J. L., \& Slobin, D. I. (1982). Rules and Schemas in the Development and Use of the English Past Tense. Language, 58(2), 265-289.

Chwilla, D. J., Brown, C. M., \& Hagoort, P. (1995). The N400 as a function of the level of processing. Psychophysiology, 32(3), 274-285.

Clahsen, H., Eisenbeiss, S., Hadler, M., \& Sonnenstuhl, I. (2001). The Mental Representation of Inflected Words: An Experimental Study of Adjectives and Verbs in German. Language, 77(3), 510-543.

Clahsen, H., \& Felser, C. (2006). Grammatical processing in language learners. Applied Psycholinguistics, 27(1), 3-42.

de Diego Balaguer, R., Sebastian-Galles, N., Diaz, B., \& Rodriguez-Fornells, A. (2005). Morphological processing in early bilinguals: An ERP study of regular and irregular verb processing. Cognitive Brain Research, 25(1), 312-327.

Diependaele, K., Duñabeitia, J. A., Morris, J., \& Keuleers, E. (2011). Fast morphological effects in first and second language word recognition. Journal of Memory and Language, 64, 344-358.

Dussias, P. E. (2003). Syntactic ambiguity resolution in L2 learners. Studies in Second Language Acquisition, 25(04), 529-557.

Dussias, P. E., \& Sagarra, N. (2007). The effect of exposure on syntactic parsing in Spanish-English bilinguals. Bilingualism: Language and Cognition, 10(01), $101-116$

Flege, J. E. (2009). Give input a chance. Input matters in SLA, 175-190.

Flege, J. E., \& Liu, S. (2001). The effect of experience on adults' acquisition of a second language. Studies in Second Language Acquisition, 23(04), 527-552. 
Frenck-Mestre, C. (2002). An on-line look at sentence processing in the second language. In J. Altarriba \& R. Herridia (Eds.), Bilingual Sentence Processing (pp. 218-236). Amsterdam: Elsevier.

Friederici, A. D. (2002). Towards a neural basis of auditory sentence processing. Trends in Cognitive Sciences, 6(2), 78-84.

Frost, R., Deutsch, A., \& Forster, K. I. (2000). Decomposing Morphologically Complex Words in a Nonlinear Morphology. Journal of Experimental Psychology: Learning, memory and Cognition, 26(3), 751-765.

Frost, R., Deutsch, A., Gilboa, O., Tannenbaum, M., \& Marslen-Wilson, W. D. (2000). Morphological priming: Dissociation of phonological, semantic, and morphological factors. Memory \& Cognition, 28(8), 1277-1288.

Gillon-Dowens, M., Vergara, M., Barber, H. A., \& Carreiras, M. (2010). Morphosyntactic processing in late second-language learners. Journal of Cognitive Neuroscience, 22(8), 1870-1887.

Gor, K. (2010). Beyond the Obvious: Do Second Language Learners Process Inflectional Morphology? Language Learning, 60(1), 1-20.

Gor, K., \& Cook, S. (2010). Nonnative processing of verbal morphology: In search of regularity. Language Learning, 60(1), 88-126.

Gor, K., \& Long, M. H. (2009). Input and second language processing. Handbook of second language acquisition, 445-472.

Grainger, J., Muneaux, M., Farioli, F., \& Ziegler, J. C. (2005). Effects of phonological and orthographic neighbourhood density interact in visual word recognition. The Quarterly Journal of Experimental Psychology Section A, 58(6), 981-998. 
Grosjean, F. (1998). Studying bilinguals: Methodological and conceptual issues. Bilingualism: Language and Cognition, 1(2), 131-149.

Hahne, A. (2001). What's Different in Second-Language Processing? Evidence from Event-Related Brain Potentials. Journal of Psycholinguistic Research, 30(3), 251-266.

Hahne, A., Mueller, J. L., \& Clahsen, H. (2006). Morphological Processing in a Second Language: Behavioral and Event-related Brain Potential Evidence for Storage and Decomposition. J. Cogn. Neurosci., 18(1), 121-134.

Hartshorne, J. K., \& Ullman, M. T. (2006). Why girls say 'holded' more than boys. Developmental Science, 9(1), 21-32.

Hopp, H. (2010). Ultimate attainment in L2 inflection: Performance similarities between non-native and native speakers. Lingua, 120(4), 901-931.

Johnson, J. S., \& Newport, E. L. (1989). Critical period effects in second language learning: The influence of maturational state on the acquisition of English as a second language. Cognitive Psychology, 21(1), 60-99.

Just, M. A., Carpenter, P. A., \& Woolley, J. D. (1982). Paradigms and processes in reading comprehension. Journal of Experimental Psychology: General, 111(2), $228-238$

Kirkici, B. (2005). Words and rules in L2 processing: An analysis of the dualmechanism model. Middle East Technical University, Ankara.

Kutas, M., \& Federmeier, K. D. (2000). Electrophysiology reveals semantic memory use in language comprehension. Trends in Cognitive Sciences, 4(12), 463-470.

Lehtonen, M., Niska, H., Wande, E., Niemi, J., \& Laine, M. (2006). Recognition of inflected words in a morphologically limited language: frequency effects in 
monolinguals and bilinguals. Journal of psycholinguistic research, 35(2), 121146.

Longworth, C. E., Marslen-Wilson, W. D., Randall, B., \& Tyler, L. K. (2005). Getting to the meaning of the regular past tense: evidence from neuropsychology. Journal of cognitive neuroscience, 17(7), 1087-1097.

Lukacs, Á., \& Pléh, C. (1999). Hungarian cross-modal priming and treatment of nonsense words supports the dual-process hypothesis. Behavioural and Brain Science, 2(6), 1030-1031.

MacIntyre, P. D., Noels, K. A., \& Clément, R. (1997). Biases in Self-Ratings of Second Language Proficiency: The Role of Language Anxiety. Language Learning, $47(2), 265-287$.

Marcus, G. F., Brinkmann, U., Clahsen, H., Wiese, R., \& Pinker, S. (1995). German Inflection: The Exception That Proves the Rule. Cognitive Psychology, 29(3), 189-256.

Marinis, T. (2003). Psycholinguistic techniques in second language acquisition research. Second Language Research, 19(2), 144.

Marinis, T., Roberts, L., Felser, C., \& Clahsen, H. (2005). Gaps in second language processing. Studies in Second Language Acquisition, 27(01), 53-78.

Marslen-Wilson, W. D., \& Tyler, L. K. (1997). Dissociating types of mental computation. Nature, 387(6633), 592-594.

McClelland, J. L., \& Patterson, K. (2002). Rules or connections in past-tense inflections: what does the evidence rule out? Trends in Cognitive Sciences, $6(11), 465-472$. 
Meunier, F., \& Marslen-Wilson, W. D. (2000). Regularity and irregularity in French inflectional morphology. Paper presented at the 22nd Annual Conference of the Cogntive Science Society, Mahwa, New Jersey.

Miozzo, M. (2003). On the processing of regular and irregular forms of verbs and nouns: evidence from neuropsychology. Cognition, 87(2), 101-127.

Morgan Short, K., Sanz, C., Steinhauer, K., \& Ullman, M. T. (2010). Second Language Acquisition of Gender Agreement in Explicit and Implicit Training Conditions: An Event Related Potential Study. Language learning, 60(1), 154-193.

Münte, T. F., Say, T., Clahsen, H., Schiltz, K., \& Kutas, M. (1999). Decomposition of morphologically complex words in English: evidence from event-related brain potentials. Cognitive Brain Research, 7(3), 241-253.

Muñoz, C. (2008). Symmetries and Asymmetries of Age Effects in Naturalistic and Instructed L2 Learning. Applied Linguistics, 29(4), 578-596.

Neubauer, K., \& Clahsen, H. (2009). Decomposition of Inflected Words in a Second Language: An Experimental Study of German Participles. Studies in Second Language Acquisition, 31, 403-435.

Newman, A. J., Ullman, M. T., Pancheva, R., Waligura, D. L., \& Neville, H. J. (2007). An ERP study of regular and irregular English past tense inflection. NeuroImage, 34(1), 435-445.

Orsolini, M., \& Marslen-Wilson, W. D. (1997). Universals in Morphological Representation: Evidence from Italian. Language and Cognitive Processes, 12(1), 1-47.

Paradis, M. (2004). A Neurolinguistic Theory of Bilingualism. Amsterdam: Benjamins. 
Penke, M., Weyerts, H., Gross, M., Zander, E., Münte, T. F., \& Clahsen, H. (1997). How the brain processes complex words: an event-related potential study of German verb inflections. Cognitive Brain Research, 6(1), 37-52.

Pinker, S. (1999). Words and Rules: The ingredients of grammar. New York: Basic Books.

Pinker, S., \& Prince, A. (1988). On language and connectionism: analysis of a parallel distributed model of language acquisition. Cognition, 28(1-2), 73-193.

Pinker, S., \& Ullman, M. T. (2002). The past and future of the past tense. Trends in Cognitive Sciences, 6(11), 456-463.

Pliatsikas, C., \& Marinis, T. (under review). Processing empty categories in a second language. Does naturalistic exposure fill the gap?

Portin, M., Lehtonen, M., \& Laine, M. (2007). Processing of inflected nouns in late bilinguals. Applied Psycholinguistics, 28(01), 135-156.

Prado, E. L., \& Ullman, M. T. (2009). Can imageability help us draw the line between storage and composition? Journal of Experimental Psychology: Learning, Memory, and Cognition, 35(4), 849.

Rastle, K., Davis, M., \& New, B. (2004). The broth in my brother's brothel: Morphoorthographic segmentation in visual word recognition. Psychonomic Bulletin \& Review, 11(6), 1090-1098.

Rastle, K., \& Davis, M. H. (2003). Reading morphologically complex words. In S. Kinoshita \& S. J. Lupker (Eds.), Masked Priming: The State of the Art. New York: Psychology Press.

Reid, A., \& Marslen-Wilson, W. D. (2002). Regularity and Irregularity in an Inflectionally Complex Language: Evidence from Polish. Paper presented at the 
23rd Annual Conference of the Cognitive Science Society Mahwah, New Jersey.

Rodriguez-Fornells, A., Clahsen, H., Lleó, C., Zaake, W., \& Münte, T. F. (2001).

Event-related brain responses to morphological violations in Catalan. Cognitive Brain Research, 11(1), 47-58.

Rossi, S., Gugler, M. F., Friederici, A. D., \& Hahne, A. (2006). The Impact of Proficiency on Syntactic Second-language Processing of German and Italian: Evidence from Event-related Potentials. Journal of Cognitive Neuroscience, 18(12), 2030-2048.

Rumelhart, D. E., \& McClelland, J. L. (1986). On learning the past tense of English verbs. In J. L. McClelland \& D. E. Rumelhart (Eds.), Parallel Distributed Processing: Explorations in the microstructures of cognition (Vol. 2, pp. 216271). Cambridge, Massachusetts; London, England: The MIT Press.

Schneider, W., Eschman, A., \& Zuccolotto, A. (2002a). E-Prime Reference Guide. Pittsburgh: Psychology Software Tools Inc.

Schneider, W., Eschman, A., \& Zuccolotto, A. (2002b). E-Prime User's Guide. Pittsburgh: Psychology Software Tools Inc.

Silva, R., \& Clahsen, H. (2008). Morphologically complex words in L1 and L2 processing: Evidence from masked priming experiments in English. Bilingualism: Language and Cognition, 11(2), 245-260.

Sonnenstuhl, I., Eisenbeiss, S., \& Clahsen, H. (1999). Morphological priming in the German mental lexicon. Cognition, 72(3), 203-236. 
Tsapkini, K., Jarema, G., \& Kehayia, E. (2002). Regularity Revisited: Evidence from Lexical Access of Verbs and Nouns in Greek. Brain and Language, 81(1-3), 103-119.

Tyler, L. K., Marslen-Wilson, W. D., \& Stamatakis, E. A. (2005). Differentiating lexical form, meaning, and structure in the neural language system. Proceedings of the National Academy of Sciences of the United States of America, 102(23), 8375-8380.

Tyler, L. K., Stamatakis, E. A., Post, B., Randall, B., \& Marslen-Wilson, W. D. (2005). Temporal and frontal systems in speech comprehension: An fMRI study of past tense processing. Neuropsychologia, 43(13), 1963-1974.

UCLES. (2001). Quick Placement Test (250 User CD-ROM Pack). Oxford: Oxford University Press.

Ullman, M. T. (2001a). The neural basis of lexicon and grammar in first and second language: the declarative/procedural model. Bilingualism: Language and Cognition, 4(2), 105-122.

Ullman, M. T. (2001b). A neurocognitive perspective on language: The declarative/procedural model. Nature reviews neuroscience, 2(10), 717-726.

Ullman, M. T. (2004). Contributions of memory circuits to language: the declarative/procedural model. Cognition, 92(1-2), 231-270.

Ullman, M. T., Pancheva, R., Love, T., Yee, E., Swinney, D., \& Hickok, G. (2005). Neural correlates of lexicon and grammar: Evidence from the production, reading, and judgment of inflection in aphasia. Brain and Language, 93(2), 185238. 
Veríssimo, J., \& Clahsen, H. (2009). Morphological priming by itself: A study of Portuguese conjugations. Cognition, 112(1), 187-194. 


\section{Tables}

Table 1. L2 learners' linguistic background and self-rating

\begin{tabular}{lccc}
\hline & NE (SD) & CE (SD) & p value \\
\hline Years or residency in the UK & $6.56(4.68)$ & 0 & $<0.001^{*}$ \\
Daily use of English (\%) & $56.93(22)$ & $16.16(11)$ & $<0.001^{*}$ \\
Daily use of Greek (\%) & $42.07(22)$ & $82.57(12)$ & $<0.001^{*}$ \\
Daily use of other language (\%) & $0.83(1.59)$ & $1.27(3.87)$ & 0.571 \\
Age of onset of English lessons & $8.83(2.42)$ & $8.11(1.58)$ & 0.18 \\
Years of learning English in a classroom setting & $8.53(3.32)$ & $8.47(2.51)$ & 0.93 \\
Self rating in speaking English (1-6,1=poor) & $4.73(0.64)$ & $4.23(0.67)$ & $0.005^{*}$ \\
Self rating in writing English (1-6,1=poor) & $4.9(0.71)$ & $4.3(0.87)$ & $0.005^{*}$ \\
Self rating in listening English (1-6,1=poor) & $4.9(0.71)$ & $4.43(0.93)$ & $0.034^{*}$ \\
Self rating in reading English (1-6,1=poor) & $5.03(0.76)$ & $4.76(0.67)$ & 0.159 \\
QPT score (\%) & $83.97(8.05)$ & $76.8(7.75)$ & $<0.001^{*}$ \\
\hline NE = naturalistic exposure, CE = Classroom exposure, QPT Q Quick Placement Test
\end{tabular}


Table 2: Mean length, orthographic neighbourhood density and frequency per condition

\begin{tabular}{|c|c|c|c|c|c|c|}
\hline \multirow{3}{*}{ Verb type } & \multicolumn{4}{|c|}{ Orthographic } & & \\
\hline & \multicolumn{2}{|c|}{ Length } & \multicolumn{2}{|c|}{ neighbourhood* } & \multicolumn{2}{|c|}{ Frequency $^{+}$} \\
\hline & Mean (SD.) & Range & Mean (SD.) & Range & Mean (SD.) & Range \\
\hline Regular & $6(1)$ & $4-8$ & $5(4)$ & $0-17$ & 435 (366) & $64-1610$ \\
\hline Irregular & $5(1.5)$ & $3-10$ & $7.5(7.3)$ & $0-27$ & $462(556)$ & $11-2139$ \\
\hline Regularised & $6.2(0.9)$ & $5-9$ & $5.7(3.7)$ & $0-12$ & $\mathrm{n} / \mathrm{a}$ & $\mathrm{n} / \mathrm{a}$ \\
\hline Irregularised & $4.7(1.2)$ & $3-9$ & $5.3(5.1)$ & $0-21$ & $\mathrm{n} / \mathrm{a}$ & $\mathrm{n} / \mathrm{a}$ \\
\hline $\bar{F}$ & 11.23 & & 1.39 & & 0.051 & \\
\hline $\mathrm{p}$ & $<0.001$ & & 0.248 & & 0.822 & \\
\hline \multicolumn{7}{|c|}{ *Number of orthographic neighbours, measured as the number of other words of the same length that } \\
\hline
\end{tabular}


Table 3: Accuracy scores in percentage per group (standard deviation)

\begin{tabular}{lcccc}
\hline & $\mathrm{NS}$ & $\mathrm{NE}$ & $\mathrm{CE}$ & $\mathrm{p}$ value \\
\hline Regular & $97.7 \%(3.2)$ & $98 \%(3.3)$ & $97.6 \%(2.8)$ & 0.914 \\
Irregular & $96.6 \%(3.6)$ & $97 \%(4.4)$ & $96.3 \%(2.8)$ & 0.937 \\
Regularised & $95.1 \%(4.8)$ & $95.6 \%(6.4)$ & $93.6 \%(3.5)$ & 0.279 \\
Irregularised & $97.6 \%(2.8)$ & $98 \%(2.8)$ & $97.9 \%(2.8)$ & 0.817 \\
\hline
\end{tabular}


Table 4: Mean RTs in milliseconds (standard deviation) per segment and condition

\begin{tabular}{|c|c|c|c|}
\hline \multirow[t]{2}{*}{ Condition } & \multicolumn{3}{|c|}{ Segment } \\
\hline & 3 & 4 & 5 \\
\hline \multicolumn{4}{|l|}{ NS } \\
\hline Regular & $966(190)$ & $599(95)$ & 701 (134) \\
\hline Irregular & 967 (164) & $572(81)$ & $648(117)$ \\
\hline Regularised & $916(164)$ & 605 (107) & 775 (136) \\
\hline Irregularised & 864 (153) & $672(141)$ & $817(138)$ \\
\hline \multicolumn{4}{|l|}{$\mathbf{N E}$} \\
\hline Regular & $1200(211)$ & 649 (92) & $798(122)$ \\
\hline Irregular & $1232(188)$ & $616(86)$ & 735 (106) \\
\hline Regularised & $1144(181)$ & 709 (128) & $936(185)$ \\
\hline Irregularised & $1054(211)$ & 706 (142) & 907 (167) \\
\hline \multicolumn{4}{|l|}{$\mathbf{C E}$} \\
\hline Regular & $1196(164)$ & $609(81)$ & 772 (107) \\
\hline Irregular & 1214 (177) & $566(74)$ & $723(111)$ \\
\hline Regularised & $1124(156)$ & $631(101)$ & $877(145)$ \\
\hline Irregularised & $1007(135)$ & 667 (134) & $920(158)$ \\
\hline
\end{tabular}


Table 5: List of real verbs used at the critical segment

\begin{tabular}{|c|c|c|c|c|c|c|c|}
\hline \multicolumn{4}{|c|}{ Regular } & \multicolumn{4}{|c|}{ Irregular } \\
\hline & Len. & Orth. N. & Freq. & & Len. & Orth. N. & Freq. \\
\hline accepted & 8 & 1 & 305 & arose & 5 & 2 & 63 \\
\hline acted & 5 & 2 & 90 & ate & 3 & 15 & 180 \\
\hline added & 5 & 2 & 388 & began & 5 & 8 & 1,585 \\
\hline asked & 5 & 1 & 1,610 & bought & 6 & 4 & 296 \\
\hline called & 6 & 10 & 1,399 & brought & 7 & 2 & 856 \\
\hline cared & 5 & 17 & 73 & chose & 5 & 7 & 145 \\
\hline carried & 7 & 7 & 442 & dealt & 5 & 1 & 71 \\
\hline caused & 6 & 2 & 266 & drank & 5 & 6 & 154 \\
\hline covered & 7 & 4 & 297 & fed & 3 & 17 & 138 \\
\hline denied & 6 & 4 & 96 & flew & 4 & 10 & 101 \\
\hline died & 4 & 12 & 434 & forgave & 7 & 1 & 11 \\
\hline entered & 7 & 1 & 191 & fought & 6 & 3 & 128 \\
\hline forced & 6 & 5 & 290 & held & 4 & 12 & 753 \\
\hline formed & 6 & 9 & 225 & hung & 4 & 11 & 197 \\
\hline happened & 8 & 0 & 632 & knew & 4 & 3 & 1,988 \\
\hline helped & 6 & 3 & 270 & left & 4 & 8 & 1,145 \\
\hline killed & 6 & 6 & 334 & meant & 5 & 2 & 489 \\
\hline learned & 7 & 2 & 64 & paid & 4 & 11 & 420 \\
\hline lived & 5 & 12 & 476 & ran & 3 & 27 & 490 \\
\hline moved & 5 & 7 & 612 & sang & 4 & 19 & 83 \\
\hline offered & 7 & 0 & 324 & sent & 4 & 18 & 524 \\
\hline
\end{tabular}




\begin{tabular}{|c|c|c|c|c|c|c|c|}
\hline opened & 6 & 3 & 469 & shook & 5 & 5 & 304 \\
\hline served & 6 & 3 & 187 & slept & 5 & 2 & 118 \\
\hline started & 7 & 4 & 673 & sought & 6 & 4 & 129 \\
\hline talked & 6 & 6 & 307 & spent & 5 & 3 & 467 \\
\hline used & 4 & 2 & 508 & struck & 6 & 0 & 193 \\
\hline waited & 6 & 8 & 225 & taught & 6 & 2 & 216 \\
\hline walked & 6 & 6 & 545 & thought & 7 & 0 & 2,139 \\
\hline wanted & 6 & 8 & 1,138 & understood & 10 & 0 & 249 \\
\hline wished & 6 & 4 & 173 & won & 3 & 23 & 235 \\
\hline
\end{tabular}

Len.: Length

Orth. N.: Orthographic Neighbourhood density

Freq.: Frequency 
Table 6: List of non-words used at the critical segment

\begin{tabular}{|c|c|c|c|c|c|}
\hline \multicolumn{3}{|c|}{ Regularised } & \multicolumn{3}{|c|}{ Irregularised } \\
\hline & Len & Orth. N. & & Len & Orth. N. \\
\hline becomed & 7 & 1 & agred & 5 & 2 \\
\hline breaked & 7 & 5 & allew & 5 & 3 \\
\hline builded & 7 & 1 & applought & 9 & 0 \\
\hline catched & 7 & 8 & arrove & 6 & 1 \\
\hline comed & 5 & 12 & chonge & 6 & 1 \\
\hline drawed & 6 & 2 & drep & 4 & 6 \\
\hline drived & 6 & 4 & ent & 3 & 7 \\
\hline falled & 6 & 11 & exast & 5 & 3 \\
\hline feeled & 6 & 7 & foce & 4 & 4 \\
\hline finded & 6 & 5 & follew & 6 & 1 \\
\hline forgetted & 9 & 0 & hopt & 4 & 6 \\
\hline gived & 5 & 9 & joun & 4 & 6 \\
\hline growed & 6 & 4 & lik & 3 & 8 \\
\hline heared & 6 & 11 & loke & 4 & 17 \\
\hline hided & 5 & 7 & ned & 3 & 16 \\
\hline keeped & 6 & 4 & pess & 4 & 21 \\
\hline leaded & 6 & 11 & plaid & 5 & 2 \\
\hline losed & 5 & 10 & ploce & 5 & 1 \\
\hline meeted & 6 & 1 & provt & 5 & 1 \\
\hline rided & 5 & 7 & raught & 6 & 3 \\
\hline selled & 6 & 6 & semt & 4 & 6 \\
\hline
\end{tabular}




\begin{tabular}{|c|c|c|c|c|c|}
\hline shooted & 7 & 4 & shew & 4 & 12 \\
\hline sitted & 6 & 4 & soov & 4 & 2 \\
\hline speaked & 7 & 4 & staid & 5 & 4 \\
\hline standed & 7 & 1 & stopt & 5 & 3 \\
\hline taked & 5 & 12 & trew & 4 & 7 \\
\hline telled & 6 & 7 & turnt & 5 & 3 \\
\hline throwed & 7 & 1 & visat & 5 & 2 \\
\hline weared & 6 & 8 & waught & 6 & 3 \\
\hline writed & 6 & 3 & werk & 4 & 8 \\
\hline
\end{tabular}

Len.: Length

Orth. N.: Orthographic Neighbourhood density 


\section{Endnotes}

${ }^{1}$ However, it should be noted that some studies have shown that women tend to store even regularly inflected forms, an effect not common in men (Hartshorne \& Ullman, 2006). In addition, Prado \& Ullman have suggested that the imageability of a form affects its retrieval (Prado \& Ullman, 2009).

${ }^{2} \mathrm{We}$ controlled for the properties of the base forms, in addition to the inflected forms, and especially their frequency, because it has been suggested that, if inflected forms are decomposed, the speed by which they are processed may be influenced by the frequency of the base forms (Gor, 2010).

${ }^{3}$ To assess whether the difference in length between regular and irregular past tense forms affected the RTs, a regression analysis was conducted in the critical segment with the length of the verb as the predicting variable - see results section.

${ }^{4}$ All analyses in the Results section are subject analyses. No items analyses were conducted because our items were not repeated across the four conditions.

${ }^{5}$ A relatively high cut-off point was chosen because we wanted to apply the same cut-off point in all segments and groups. A cut-off point of $4000 \mathrm{~ms}$ ensured that the same amount of data points were affected per group. A lower threshold would cause more data points being excluded from non-native compared to native speakers in the non-critical segments. For example, with a cut-off point of $4000 \mathrm{~ms}$, the percentage of extreme values for Segment 6 is not significantly different between NS, NE and CE $(0.1 \%, 0.2 \%$ and $0.2 \%$, respectively). A cut-off point of $3000 \mathrm{~ms}$ for the same data would exclude $0.3 \%$, $1 \%$ and $1.1 \%$ of the data of the three groups respectively, introducing a significant between-groups difference. In terms of the critical segment, a threshold of 3000 would only affect two additional data points per group, and thus, it would not change our results.

${ }^{6}$ Although this is a possible explanation for the distinction between NE vs. CE in the processing of regularised forms, it is also crucial to note that both groups of $\mathrm{L} 2$ learners received the same type and amount of classroom exposure before the NE group moved to the UK. Since both groups are expected to have developed the same inflectional processing strategies through classroom instruction, the NEspecific sensitivity to form frequency suggests immersion-based changes in inflectional processing strategies. This is an interesting suggestion, but must be treated with caution, because the between-group differences were observed only for non-words and not for real inflected verbs. Therefore, only a hint for exposure-type related effects is provided by this finding, which is in need of further investigation. ${ }^{7}$ Our data cannot provide evidence about whether or not high proficiency level is a prerequisite for structure-based processing of regular inflection because we only tested participants at the higher end of the proficiency scale. Future research including L2 learners of low to medium proficiency level is necessary to address this issue. 